\title{
Families of patients with mental illness revised their ideas of what it means to live a "normal" life
}

Rose L, Mallinson RK, Walton-Moss B. A grounded theory of families responding to mental illness. West J Nurs Res 2002;24:516-36.

\section{QUESTION: How do families manage the experience of mental illness?}

\section{Design}

Grounded theory.

\section{Setting}

A medical institution in the US.

\section{Participants}

29 family members (age range $18-73$ y; $66 \%$ women; $66 \%$ white, 28\% African-American, 7\% Hispanic) of 17 patients who had schizophrenia, major depression, or bipolar disorder. Patients consented to researchers contacting their relatives. Family members had $\geq 1$ weekly contact with patients. Most patients had a history of $\geq 3$ hospital admissions.

\section{Methods}

Three 60-90 minute semistructured interviews were planned with each family over 2 years (soon after initial contact, at $6 \mathrm{mo}$, and at $1 \mathrm{y}$ ). Participants were asked to talk about their experiences of the illness, observations of social or cultural issues, and thoughts about the future. Interviews were audiotaped, transcribed, and analysed using the constant comparative method.

\section{Main findings}

The basic social problem facing families was living with the ambiguity of mental illness. This was resolved through the basic sociopsychological process of pursuing normalcy for the patient. Families expressed anger and frustration related to their expectations and ability to help patients conform or be happy. (1) Confronting ambiguity: families, on learning of the illness, expressed feelings of unreality and disruption. Keeping watch/losing trust: families were confronted with unpredictable behaviour and adopted an enduring stance of watching and waiting. Being consumed by the illness: families stopped everything to tend to their ill relatives. They expressed helplessness and anger at the healthcare system for poor treatment and inadequate information. Making sense of behaviour as illness-based: families described a sense of crisis and an urgent need to find answers. (2) Seeking control over the illness: with time, families found ways to regain control. Containing losses/ managing grief: families dealt with multiple losses, including loss of pre-illness family relationships. Questioning responsibility for symptom management: families varied in their ideas about who was responsible for managing the illness and which aspects could be managed. Their lives alternated between periods of calm and hope and periods of crisis. (3) Adopting a stance of possibilities and realities: families moved from initial shock, fear, and frustration to intense grief for what was lost; some also felt cautious optimism for the future.
Reaffirming hope: families were hopeful if key events happened, such as a patient finding a job, or if they realised that a hopeful stance was more helpful for patients. Resolving questions of responsibility: families either communicated an expectation of self responsibility to patients or continued to accept it for themselves. Families accepted limitations on what they could do. Redefining relationships: families either worked to maintain the status quo in relationships with patients or pushed for change. Maintaining stability while striving for growth: some families, who had experienced violent behaviour by patients or gone through several committal processes, worked at maintaining calm and avoiding the chaos of disruptive behaviour. Reaching conclusions: this was characterised by unambiguous statements of priorities, decisions, and evaluations of situations. Families revised their ideas of what it meant to be "normal" to include their wish that the patient be happy.

\section{Conclusion}

Families of patients with mental illness tried to help patients pursue as "normal" a life as possible but had to revise their ideas of what "normal" meant so that it included their wish for the patient to be happy.

\section{COMMENTARY}

Rose $e t$ al examined the experiences of families of people diagnosed with serious mental illness. Their grounded theory study was based on repeated interviews over a 2 year period. Findings add to the literature because many of the previous qualitative studies were based on a single interview $w^{1-2}$ and few extended over a 1 year period. ${ }^{3}$ Although many previous family studies have used the perspective of burden, this study discovered a process of rethinking what it is to be "normal".

The sample was drawn from family members of patients with serious mental illness who were enrolled in hospital and community based programmes. The sample included family members of people with schizophrenia, major depression, and bipolar disorder, and findings represent a range of experiences. It is unclear whether substantive differences exist for family members of each of these groups, although none were reported. This question needs to be examined in future studies.

The identification of the basic social process of pursuing normalcy is an important consideration for nurses. This finding could assist in the framing of educational offerings and other supportive programmes. The description of being consumed by the illness in the initial stages is also important for healthcare professionals to understand. By cutting themselves off from their usual support systems at this critical time, families may leave themselves vulnerable and isolated. Nurses can have a key role in assisting families to understand the process of illness and recovery and support their complex struggle to come to a new understanding of normalcy.

Cheryl Forchuk, RN, PhD Professor/Scientist University of Western Ontario/Lawson Health Research Institute London Health Sciences Centre London, Ontario, Canada

1 Karp DA, Tanarugsachock V. Mental illness, caregiving, and emotion management. Qual Health Res 2000;10:6-25.

Mays GD, Lund CH. Male caregivers of mentally ill relatives. Perspect Psychiatr Care 1999;35:19-28.

Najarian SP. Family experience with positive client response to clozapine. Arch Psychiatr Nurs 1995;9:11-21. 